\title{
Análise do posicionamento de artistas visuais manauaras sobre a criação de um sistema de comunicação para a divulgação de suas obras
}

\author{
Analysis of the positioning of visual artists from Manaus - Brazil on \\ the creation of a communication system for the dissemination of \\ their works
}

\begin{abstract}
Anna Lôyde Abreu de Araújo
Universidade Federal do Amazonas

anna.Icpa@gmail.com

Karla Mazarelo Maciel Pacheco

Universidade Federal do Amazonas

karlamazarelo@ufam.edu.br
\end{abstract}

\section{PROJËTICA}

\section{COMO CITAR ESTE ARTIGO:}

ARAUJO, Anna Lôyde Abreu de; PACHECO, Karla Mazarelo Maciel. Análise do posicionamento de artistas visuais manauaras sobre a criação de um sistema de comunicação para a divulgação de suas obras. Projética, Londrina, v. 12, n. 1, p. 14-38, 2021.

DOI: 10.5433/2236-2207.2021v12n1p14

Submissão: 26-03-2019

Aceite: $25-10-2019$ 
Análise do posicionamento... suas obras

ARAUJO, Anna Lôyde Abreu de; PACHECO, Karla Mazarelo Maciel

RESUMO: Este trabalho é parte de uma pesquisa de dissertação de mestrado cujo objetivo é propor um sistema de comunicação que promova a divulgação do trabalho artístico visual manauara. Para isso, o artigo tem como abordagem a análise do posicionamento de artistas visuais manauaras sobre a criação desse sistema. A estrutura deste conteúdo contempla uma pesquisa qualitativa, do tipo bibliográfica e documental, com utilização de entrevistas com especialistas do campo da arte. Como resultado, apresenta-se a definição do produto mais apropriado a ser desenvolvido.

Palavras-chave: Sistema de comunicação. Artes visuais. Design.

ABSTRACT: This work is part of a master's dissertation research which aimed to propose a communication system that promotes the dissemination of the visual artistic work in Manaus - Brazil. In order to do so, this paper analyses the positioning of visual artists from Manaus - Brazil on the creation of such system. The structure includes a qualitative research of bibliographical and documental nature, and interviews with specialists of the

field of arts. As a result, we present the most appropriate format for the development of this communication product.

Keywords: Communication system. Visual arts. Design.

\section{INTRODUÇÃO}

A produção dos artistas visuais no Amazonas já atingiu altos níveis de criação, que resultaram em grandes exposições internacionais. Em Manaus, a produção local sempre esteve presente, mesmo sendo considerado que as formas de expressão artística, inclusive, "as artes visuais chegaram ao Amazonas com o dinheiro do ciclo 
Projética, Londrina, v. 12, n. 1, p. 14-38, março 2021

da borracha" (CONCULTURA, 2016, p. 47). Mas, antes mesmo desse acontecimento já havia indícios de expressões das artes visuais. A cidade "não era exatamente um deserto em se tratando de tradição artística. Desde os tempos do Império a cidade permitia o contato, ainda que intermitente, com exposições de pintura, [...]." (CONCULTURA, 2016, p. 47).

Considerando a realidade artística no Amazonas, o Ciclo da Borracha é um dos períodos que se pode destacar. Juntamente, nessa época, surgiram fotógrafos, artistas, arquitetos, escultores, todos com esperança de uma economia emergente. Prata (2017) ressalta ainda que,

[...] é possível observar que vários desses artistas acabaram trabalhando em mais de um ramo de atividade ou gênero artístico, ante a carência de profissionais atuantes desse campo. A falta de possibilidade de exercer somente a prática criativa e a submissão aos interesses das elites dominantes, uma das causas da supracitada "necrofilia artística", vai se consolidar nesse momento e pautar a estrutura do campo nesse espaço social. (PRATA, 2017, p. 159).

Já por volta de 1954, Moacir de Andrade (pintor manauara autodidata), juntamente com poetas, escritores e outros artistas, fundaram o Clube da Madrugada. Uma época de auge das artes na cidade e no estado. Várias ações, eventos, exposições surgiram e agitaram a produção artística. Toda essa agitação cultural culminou com a criação da Pinacoteca do Estado do Amazonas, no qual "abrigou um acervo museológico significativo da arte amazonense e brasileira" (PÁSCOA, 2007, p. 9).

A arte estava inserida tanto no contexto cultural quanto no comercial, promovendo e gerando renda aos artistas. Por outro lado, haviam também algumas críticas em relação ao Clube da Madrugada, em que as produções eram pautadas apenas pelo interesse de classes dominantes. 
Análise do posicionamento... suas obras ARAUJO, Anna Lôyde Abreu de; PACHECO, Karla Mazarelo Maciel

Sendo assim, com o passar do tempo, Segundo Prata (2017), os demais artistas precisavam complementar suas rendas, se mantendo financeiramente,

\begin{abstract}
[...] e como em Manaus não havia público para sustentar uma dedicação exclusiva à atividade artística criativa, vários deles acumulavam outras atividades sob a tutela do estado, tal como a de professores de arte, por exemplo, tais como seus antecessores do ciclo da borracha e de postura mais bovina. (PRATA, 2017, p. 161).
\end{abstract}

Atualmente, a realidade dos artistas ainda acompanha a necessidade de complementar a renda com demais atividades e outras práticas. Prata (2017) relata ainda que há de se considerar que esse complemento pode ser restritivo, "mas também cheio de potencialidades mercantis" (PRATA, 2017, p. 166).

Para Gombrich (2013), apesar de algumas iniciativas, ainda existe uma grande separação entre a arte "aplicada" (comercial), e a arte "pura" encontrada em exposições. Isso mostra a relevância de estreitar a comunicação entre arte e mercado, sem desvalorizar ambos os lados. A comunicação, por sua vez, se relaciona à forma que a mensagem é transmitida, à divulgação e alcance que a informação chega aos ouvintes, aos espectadores, ao público e aos próprios artistas.

Para promover o acesso à arte, bem como encará-la enquanto mercado, é válido considerar de que forma essa divulgação da arte tem se estabelecido. Um dos principais meios de divulgação do trabalho artístico na cidade acontece nas exposições em galerias. Espaço onde acontecem a visualização direta das obras e a troca entre o artista e o seu público. No livro "Transformatividade" da autora Silvana Rea, o artista Carlos Fajardo ressalta que, "a relação que se tem com o próprio trabalho é sempre renovada em uma exposição. A exposição você faz para o outro, para o público". (REA, 2000, p. 110). 
Projética, Londrina, v. 12, n. 1, p. 14-38, março 2021

Contudo, apesar da exposição ser um meio de divulgação mais reconhecido na cidade. Ela não se limita apenas a esse momento. Há várias maneiras de se divulgar o trabalho artístico, antes mesmo de ir para exposição. Os meios de comunicação vão desde os impressos, como por exemplo: as filipetas, antigamente encontradas tão comumente para a divulgação de uma exposição; os jornais, que até hoje são um meio de divulgação com grande alcance.

A necessidade de melhorias na divulgação e na gestão dessa comunicação visual é evidente. Frequentemente são os próprios artistas que tomam iniciativa para fazer sua própria divulgação. Com isso, surgem limitações por parte desses profissionais ao fazer com que seu público tenha acesso ao seu trabalho.

Portanto, contribuir com a comunicação do trabalho artístico manauara por meio da gestão do design, poderá agregar maior valor ao produto desenvolvido pelos mesmos. Com o design e o desenvolvimento de uma comunicação visual adequada e planejada, os resultados promovem benefícios culturais e sociais ao atingir novos públicos que consumirão arte. Além de fortalecer a identidade local da comunidade manauara.

Através do uso da tecnologia, surge também a possibilidade de a comunicação ter um alcance maior, permitindo e viabilizando o acesso à arte local. Com isso, tem-se a oportunidade de desenvolver um sistema inovador aliado à tecnologia, para assim ser inserido em novos meios ainda não explorados devidamente.

Ao viabilizar maior acesso à arte pela comunidade, paralelamente há o consumo da mesma. Pois, surge a possibilidade de compra da obra de um artista local, bem como a possibilidade de adquirir um produto da arte aplicada. Com isso, a arte ganha espaço no cenário mercadológico, gerando renda e economia aos profissionais da área. 
Ao viabilizar maior acesso à arte pela comunidade, paralelamente há o consumo da mesma. Pois, surge a possibilidade de compra da obra de um artista local, bem como a possibilidade de adquirir um produto da arte aplicada. Com isso, a arte ganha espaço no cenário mercadológico, gerando renda e economia aos profissionais da área. 
Projética, Londrina, v. 12, n. 1, p. 14-38, março 2021

Portanto, o ponto chave para este artigo consiste em analisar o posicionamento de artistas visuais da cidade de Manaus a respeito da criação de um sistema de comunicação mais apropriado para a divulgação de suas obras. Para isso, são propostos os seguintes objetivos específicos:

- Consultar especialistas em artes visuais na cidade de Manaus sobre os sistemas de comunicação existentes (adotados ou não) para a divulgação local de suas obras;

- Observar os tipos de sistemas de comunicação já utilizados por esses artistas;

- Identificar os tipos de trabalhos desenvolvidos na cidade pelos artistas; - Definir em conjunto com especialistas consultados, o tipo de produto a ser desenvolvido como sistema de comunicação.

\section{MATERIAIS E MÉTODOS}

A natureza do presente artigo se caracteriza como pesquisa aplicada ao gerar conhecimentos que resultaram em uma aplicação prática como solução do problema. Em relação à sua estrutura, contempla uma pesquisa qualitativa, pois os dados não são traduzidos em números. Do ponto de vista dos objetivos, a pesquisa classifica-se como exploratória e descritiva (GIL, 2002; MARCONI; LAKATOS, 2003). Quanto aos procedimentos técnicos, se caracteriza como do tipo bibliográfica, documental, ratificada um estudo de caso específico (YIN, 2001).

O presente artigo faz parte de um estudo maior, portanto os dados obtidos são a partir de referências que discutem a temática por meio da aplicação da técnica qualitativa Focus Group, com o intuito de obter percepções de um grupo de especialistas sobre questões e alternativas do objeto de estudo, gerando novas ideias, comentários e a produção de insights (KRUEGER; CASEY, 2000). 
Figura 1 - Técnica Focus Group realizada com especialistas em artes visuais da cidade de Manaus.
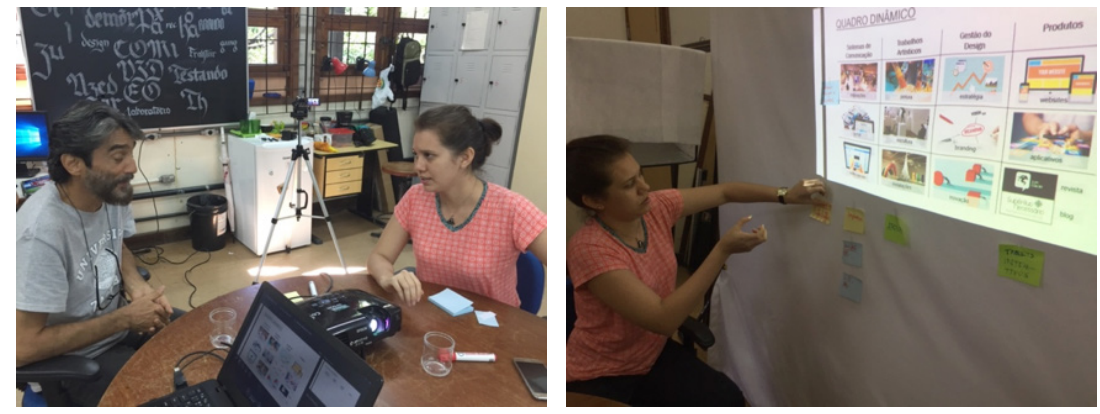

Fonte: A autora (2018).

Com base na temática e nas características do presente estudo, foram selecionados de forma intencional, quatro especialistas em Artes Visuais em constante produção na cidade de Manaus (Figura 1) para a realização da dinâmica (Focus Group) na sede da Universidade Federal do Amazonas - UFAM. Esses profissionais foram intencionalmente escolhidos por suas diferentes abordagens e influências como artistas visuais na cidade.

Para a execução da proposta, foi definido em conjunto com os especialistas consultados o tipo de produto a ser desenvolvido. Foram analisadas as opiniões dos participantes com relação aos temas que envolvem a projetação do sistema de comunicação e identificados os aspectos considerados importantes para o seu procedimento.

O primeiro especialista consultado possui graduação em Licenciatura em Artes Visuais pela Universidade Federal do Amazonas. Possui experiência com ênfase em educação e produção artística, atuando principalmente nas seguintes áreas: ilustração de livros, pintura em aquarela, escultura, arte urbana, exposições de arte e cursos livres de desenho e aquarela. Trabalhou como arte educadora ministrando cursos e oficinas, organizando exposições e eventos no Centro de Artes da Universidade Federal do Amazonas - CAUA. 
Projética, Londrina, v. 12, n. 1, p. 14-38, março 2021

O segundo especialista possui graduação em Jornalismo / Comunicação Social - Fundação Universidade do Amazonas (1976-1979); graduação em Gravura / Escola de Belas Artes - Universidade Federal do Rio de Janeiro (1980- 1983); mestrado em História e Crítica da Arte pelo Programa de Pós -graduação da Escola de Belas Artes da Universidade Federal do Rio de Janeiro (1989-1992) e doutorado em História - Programa de Pós-graduação em História Social da Universidade Federal Fluminense (2001-2005). Entre 1997 e 1998 atuou como Coordenador do Patrimônio Histórico da Secretaria de Cultura do Estado do Amazonas. Publicou dois livros, resultantes do trabalho de mestrado e de doutorado. Atuou como professor do Curso de Artes Visuais do Departamento de Artes da Universidade Federal do Amazonas. Atuou no Programa de Pós-graduação em História entre 2006 e 2013. Além das atividades acadêmicas, atua como artista plástico desde 1975, desenvolvendo obras em variados suportes, gêneros e materiais.

O terceiro especialista é mestre em Letras e Artes pela Universidade do Estado do Amazonas (2013) e possui graduação em dança pela Universidade do Estado do Amazonas (2009) e graduação em pedagogia pela Universidade Estadual do Ceará (2005). Atualmente é professor da Universidade do Estado do Amazonas, diretor geral do Centro Cultural Casarão de Ideias e da Revista Ideias Editadas. Tem experiência na área de artes, com ênfase em coreografia, gestão cultural, atuando principalmente nos seguintes temas: dança, teatro, captação de recurso, produção cultural, artes visuais e outras ações de agentes culturais.

O quarto especialista é formado em Educação Artística pela Universidade Federal do Amazonas. Pós-graduado em “História e Crítica da Arte” pela Universidade Federal do Amazonas, é mestre em "Gestão Empresarial" pela UniNilton Lins. Começou a pintar aos 12, porém apenas em 1990 participou da primeira exposição coletiva. Faz parte da quarta geração de artistas plásticos do Amazonas, participando e representando o Estado em eventos nacionais e internacionais. Desde 1992 realiza pesquisa antropológica sobre sociedades indígenas, de onde 
Análise do posicionamento... suas obras ARAUJO, Anna Lôyde Abreu de; PACHECO, Karla Mazarelo Maciel

saíram suas principais exposições, bem como, outras linhas de trabalho que vêm simultaneamente. Foi vencedor de prêmios em 1998. Já atuou como diretor na Galeria do Largo. Atualmente, é diretor de museus da Secretaria de Cultura (SEC) do Amazonas.

Para a execução da proposta, foi definido em conjunto com os especialistas consultados o tipo de produto a ser desenvolvido. Foram analisadas as opiniões dos participantes com relação à aspectos que envolvem a projetação do sistema de comunicação e identificadas sugestões consideradas importantes para o seu procedimento.

A dinâmica envolveu o questionamento sobre quatro aspectos, sendo eles: Sistemas de comunicação; Trabalhos Artísticos; Gestão do Design; e Produtos Inovadores.

Os aspectos foram determinados de acordo com a linha de pesquisa do Programa de Pós-graduação em Design inserido, que envolve: Design, Tecnologia e Inovação. Portanto, para se chegar a uma definição de Produto Inovador, é necessário saber como o produto funcionará através de uma Gestão, o qual terá como foco o Design. Para assim, compreender que tipos de Trabalhos Artísticos serão inseridos no Sistema de Comunicação. Dessa forma, a dinâmica segue uma estrutura planejada para alcançar resultados satisfatórios que condizem com a pesquisa.

Cada aspecto foi exemplificado aos participantes para melhor compreensão, e em seguida, foi solicitado a inserção de novas ideias em cada um desses itens de acordo com a percepção profissional dos especialistas em artes visuais da cidade. 
Projética, Londrina, v. 12, n. 1, p. 14-38, março 2021

\section{RESULTADOS}

São apresentados nos subtópicos seguintes, a aplicação da dinâmica (Focus Group), a discussão de seus efeitos, bem como a definição em conjunto com especialistas consultados, sobre o tipo de produto a ser desenvolvido como sistema de comunicação.

\subsection{Focus Group}

A dinâmica aplicada aos quatro especialistas em artes visuais da cidade Manaus, conforme detalhado na metodologia, envolveu o questionamento sobre os quatro aspectos já mencionados: Sistemas de comunicação; Trabalhos Artísticos; Gestão do Design; e Produtos Inovadores. Todos os itens foram exemplificados aos participantes através de um quadro ilustrativo (Quadro 1) para melhor compreensão.

Quadro 1 - Quadro ilustrativo para exemplificar a dinâmica aos especialistas participantes.

\section{QUADRO DINÂMICO}

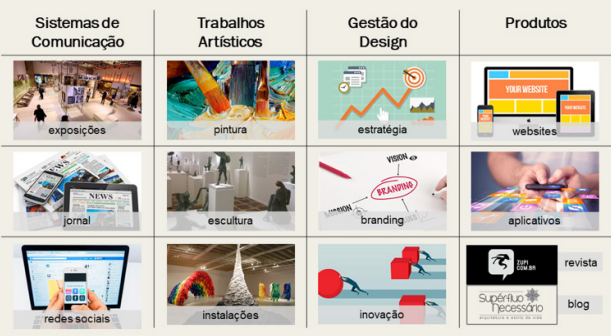

Fonte: A autora (2018). 
No primeiro aspecto, foi exemplificado: exposições, jornal e redes sociais, como uma possível forma de comunicação nas artes visuais. No segundo aspecto: pintura, escultura e instalações, como tipos de trabalhos artísticos. No terceiro aspecto: estratégia, branding e inovação, como ferramentas da gestão do design. E por fim, no quarto aspecto: websites, aplicativos, revistas e blogs, como possíveis produtos inovadores a serem desenvolvidos.

Após a explicação, os especialistas foram questionados sobre cada um dos aspectos, sendo convidados a inserirem novas ideias, de acordo com suas respectivas percepções sobre o cenário das artes visuais na cidade de Manaus (Quadro 2). Após questionamento dos aspectos, surgiram sugestões dos especialistas, no qual registraram cada uma de suas ideias em post-its (adesivos autocolantes), fixandoos na parede em que estava sendo projetado o quadro.

Quadro 2 - Quadro para preenchimento de acordo com as sugestões dos especialistas.

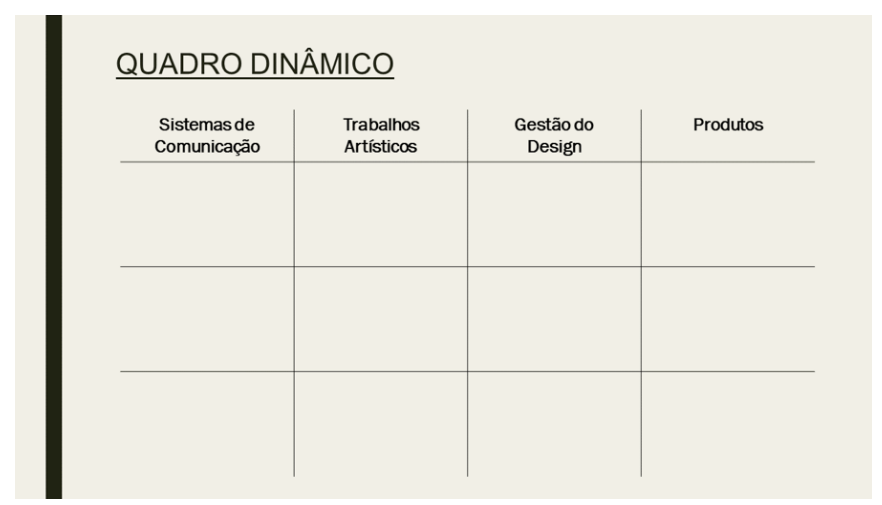

Fonte: A autora (2018). 
Projética, Londrina, v. 12, n. 1, p. 14-38, março 2021

Todos os especialistas receberam o mesmo questionamento, primeiramente referente ao aspecto "sistemas de comunicação", em que foi questionado quais os sistemas que podem ser utilizados pelos artistas para comunicarem as artes visuais na cidade de Manaus. Temos as seguintes sugestões de cada artista, conforme demostra o Quadro 3:

Quadro 3 - Sugestões dos especialistas referentes aos "sistemas de comunicação"

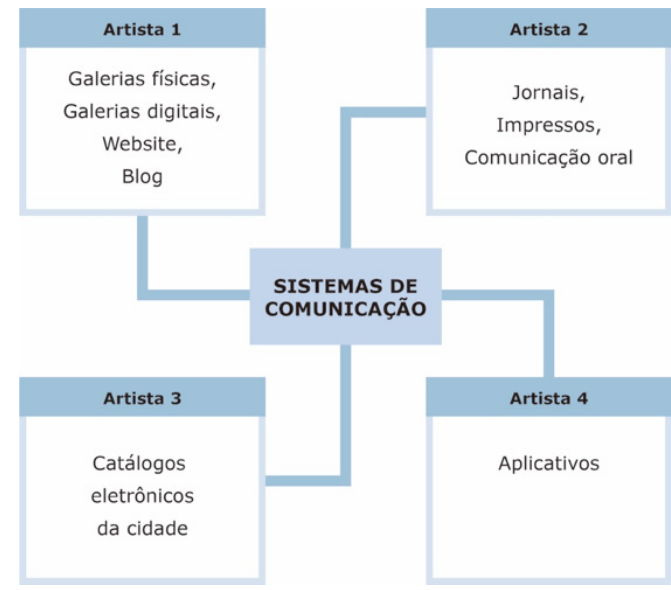

Fonte: A autora (2018).

Com as sugestões inseridas, é possível visualizar as mais diversas possibilidades de sistemas que comunicam e divulgam a arte e o artista. Umas das inserções mais discutidas foram as "galerias físicas", que segundo os especialistas tem sido o sistema mais utilizado como forma de expor o trabalho artístico local. Funcionando de forma produtiva, com a realização de várias exposições pela cidade. Sobre as "galerias digitais", os especialistas mencionaram não haver nenhuma proposta nesse sentido ainda na cidade, mas destacaram que seria uma opção de comunicação viável perante às novas tecnologias, e que já tem funcionado bem em outras cidades. 
Os outros sistemas inseridos, foram mencionados por serem utilizados também na cidade de Manaus, como jornais, impressos e comunicação oral. Foi destacado que ao longo da história da divulgação artística, esses meios foram e ainda são utilizados. Apesar de muitas vezes, não chegar a um alcance tão satisfatório. Os catálogos eletrônicos, websites, blogs e aplicativos, são sistemas ainda não bem explorados na cidade como meio de comunicação do artista e de suas obras, conforme fora mencionado por um dos especialistas e concordado por todos.

No segundo aspecto "trabalhos artísticos", foi questionado quais seriam os tipos de trabalhos artísticos visuais produzidos na cidade, a serem inseridos no sistema de comunicação. Temos as seguintes sugestões conforme demostra o Quadro 4 abaixo:

Quadro 4 - Sugestões dos especialistas referentes aos "trabalhos artísticos".

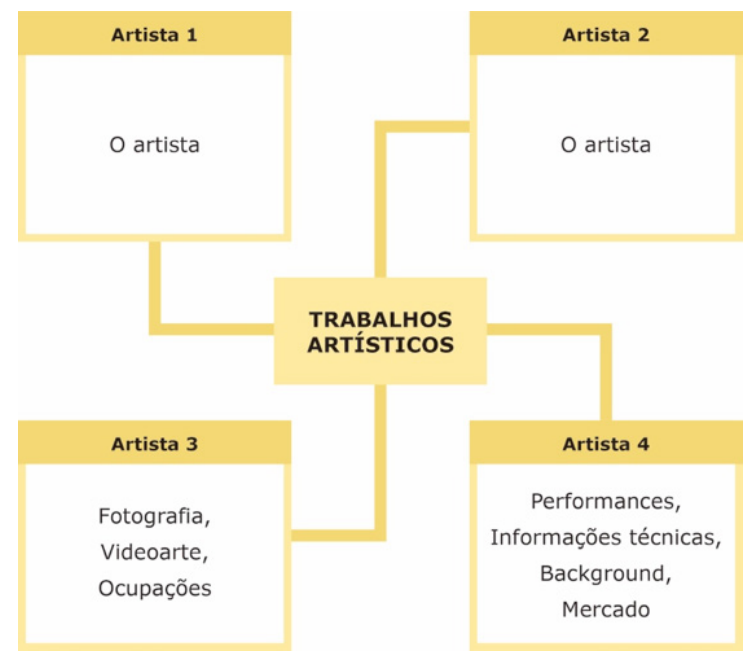

Fonte: A autora (2018). 
Projética, Londrina, v. 12, n. 1, p. 14-38, março 2021

Ao questionar sobre o devido aspecto, a intenção era captar que tipos de trabalhos artísticos visuais deveriam ser incluídos no sistema para serem melhor evidenciados, e também para delimitação da pesquisa. Portanto, os artistas 1 e 2 logo deram suas sugestões e discutiram a razão de apenas terem colocado "o artista".

Levantou-se uma discussão sobre a relação entre a divulgação do trabalho artístico visual e a divulgação do próprio artista visual em si. Segundo os artistas (1 e 2), os mesmos mencionaram que há muitos caminhos e técnicas para se expressar visualmente. E, elencar apenas alguns tipos de trabalhos, limitaria essa própria liberdade de expressão do artista visual.

Portanto, para a pesquisa gerar maior impacto, a sugestão dos artistas foi em excluir a limitação dos tipos trabalhos artísticos visuais. Como proposta, sugeriram desenvolver no sistema de comunicação, a divulgação do artista visual em si. Pois, segundo esses especialistas, o artista e sua arte são um só, não há como desvincular.

Os artistas 3 e 4 mencionaram sobre diferentes expressões que o artista visual pode explorar, além do comum, como: fotografia, produção de videoarte, ocupações, performances, informações técnicas, background, mercado. As sugestões inseridas por esses especialistas não foram tão discutidas, pois logo os mesmos entraram em concordância com os artistas 1 e 2, após discussão sobre esse aspecto de alta relevância na pesquisa. 
Levantou-se uma discussão sobre a relação entre a divulgação do trabalho artístico visual $e$ a divulgação do próprio artista visual em si. Segundo os artistas (1 e 2), os mesmos mencionaram que há muitos caminhos e técnicas para se expressar visualmente. E, elencar apenas alguns tipos de trabalhos, limitaria essa própria liberdade de expressão do artista visual. 
Projética, Londrina, v. 12, n. 1, p. 14-38, março 2021

Em relação ao terceiro aspecto "gestão do design", foi questionado quais seriam as ferramentas de gestão (conhecidas por eles) que poderiam ser utilizadas no sistema para garantir sua sobrevivência. Temos as seguintes sugestões conforme demostra o Quadro 5:

Quadro 5 - Sugestões dos especialistas referentes à "gestão do design".

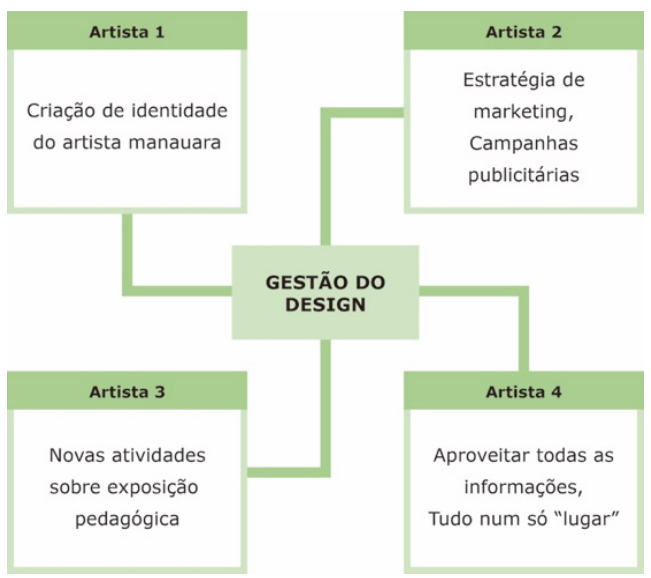

Fonte: A autora (2018).

Para a inserção de sugestões dos especialistas neste tópico, foi necessária uma explicação mais detalhada sobre "gestão do design". Após o entendimento por todos, iniciaram as inserções de como é possível relacionar a gestão do design com o artista e suas necessidades.

O artista 1 indicou a necessidade de usar a gestão do design como forma de criar uma identidade para o artista manauara. Dessa forma, seria possível facilmente reconhecê-la através de suas linguagens padronizadas (sonoras, visuais). O artista 2 mencionou a necessidade de ser criada uma estratégia de marketing e criação de campanhas publicitárias para gerar envolvimento com as pessoas, e chamar a atenção de novos públicos. $O$ artista 3 sugeriu usar a gestão do design 
como meio para inserir novas atividade sobre exposição pedagógica. E, o artista 4 entendeu que é necessário se fazer um estudo para que sejam aproveitadas todas as informações existentes sobre o assunto, e assim, poder encontrá-las em um único "lugar" (sistema). Todos os artistas ouviram as sugestões e entraram em concordância entre si.

Sendo assim, as sugestões mencionadas e discutidas pelos especialistas apontaram para o aspecto de inovação e criação de estratégias específicas para se manter um sistema de comunicação dentro do campo da arte.

Por fim, no quarto aspecto "produtos inovadores", mediante discussões anteriores, foi questionado qual seria o produto ideal a ser desenvolvido nesse sistema de comunicação. Temos as seguintes sugestões conforme demostra o Quadro 6 abaixo:

Quadro 6 - Sugestões dos especialistas referentes aos "produtos inovadores".

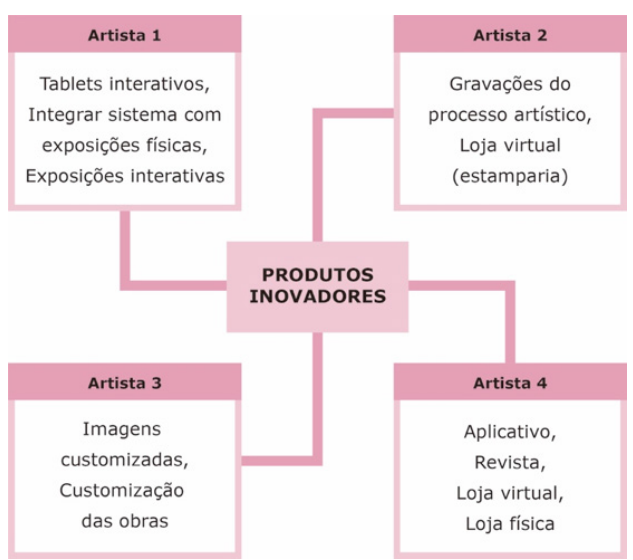

Fonte: A autora (2018). 
Projética, Londrina, v. 12, n. 1, p. 14-38, março 2021

O artista 1 sugeriu a inserção de tablets interativos para criar novas possibilidades de interação do público com a obra do artista visual. Ainda complementou, sobre a integração desse sistema com exposições físicas, gerando exposições mais interativas.

O artista 2 sugeriu gravações do processo artístico, de forma a envolver o público com a obra. Apesar de não ser um produto, o artista sugeriu um conteúdo a ser incluído no sistema. O mesmo foi bem avaliado pelos demais artistas como uma boa ideia para gerar maior envolvimento. A segunda sugestão do artista 2 foi a criação de uma loja virtual que tivesse como foco a estamparia. Ou seja, um espaço virtual para se comprar produtos estampados com obras dos artistas da cidade. A ideia foi bem recebida por todos por ser algo mais inovador no contexto local.

O artista 3 sugeriu "imagens customizadas e customização das obras", se referindo a usar as obras como inspiração para a aplicação em diferentes materiais, como bolsas, papelaria. A sugestão foi bem recebida pelos demais por se parecer com segunda a ideia do artista 2. Apenas se discutiu que seria necessário um outro profissional (designer) para gerar as estampas e customizações.

O artista 4 inseriu como primeira sugestão, a criação de aplicativos. Ideia bem relevante e adequada às novas demandas do mercado, pelo uso da tecnologia. O mesmo, também mencionou a criação de revista sobre a arte local. Dois dos especialistas discordaram da sugestão, pois não se encaixaria com um "produto inovador", em vista que já existem alguns projetos nesse sentido. A terceira sugestão do artista 4, foi igual à do artista 2: criação de uma loja virtual. Por fim, a última sugestão foi a criação de uma loja física. Ideia bem relevante e até foi mencionada por um dos especialistas que o mesmo já está viabilizando a ideia em uma galeria da cidade. 
Análise do posicionamento... suas obras ARAUJO, Anna Lôyde Abreu de; PACHECO, Karla Mazarelo Maciel

Portanto, ao observarmos o quadro e as análises feitas, é possível perceber sugestões similares entres os especialistas. Sobre as inserções "tablets interativos, exposições interativas, aplicativo, loja virtual", todos elas envolvem um sistema digital como apoio para a interação com usuários, sem abrir mão do físico, mas principalmente, integrando os dois sistemas para se complementarem.

As outras inserções semelhantes foram "imagens customizadas, customização das obras, loja virtual, loja física e loja virtual (estamparia)". O ponto em comum entre elas está relacionado ao acesso à arte, à maneira de como obter um produto da obra de um artista, e à possibilidade de a arte ganhar novas dimensões em produtos aplicados.

\subsection{Produto}

Para definição do produto a ser desenvolvido, foram analisados os quadros com as sugestões inseridas pelos especialistas. No Quadro 7 estão todos os aspectos considerados importantes e os parâmetros, por eles, determinados necessários à realização da pesquisa. As informações identificadas em $(\sqrt{ })$ representam concordância. As identificadas em (X) representam sugestões que não entraram em consentimento. 
Projética, Londrina, v. 12, n. 1, p. 14-38, março 2021

Quadro 7 - Aspectos considerados importantes pelos especialistas.

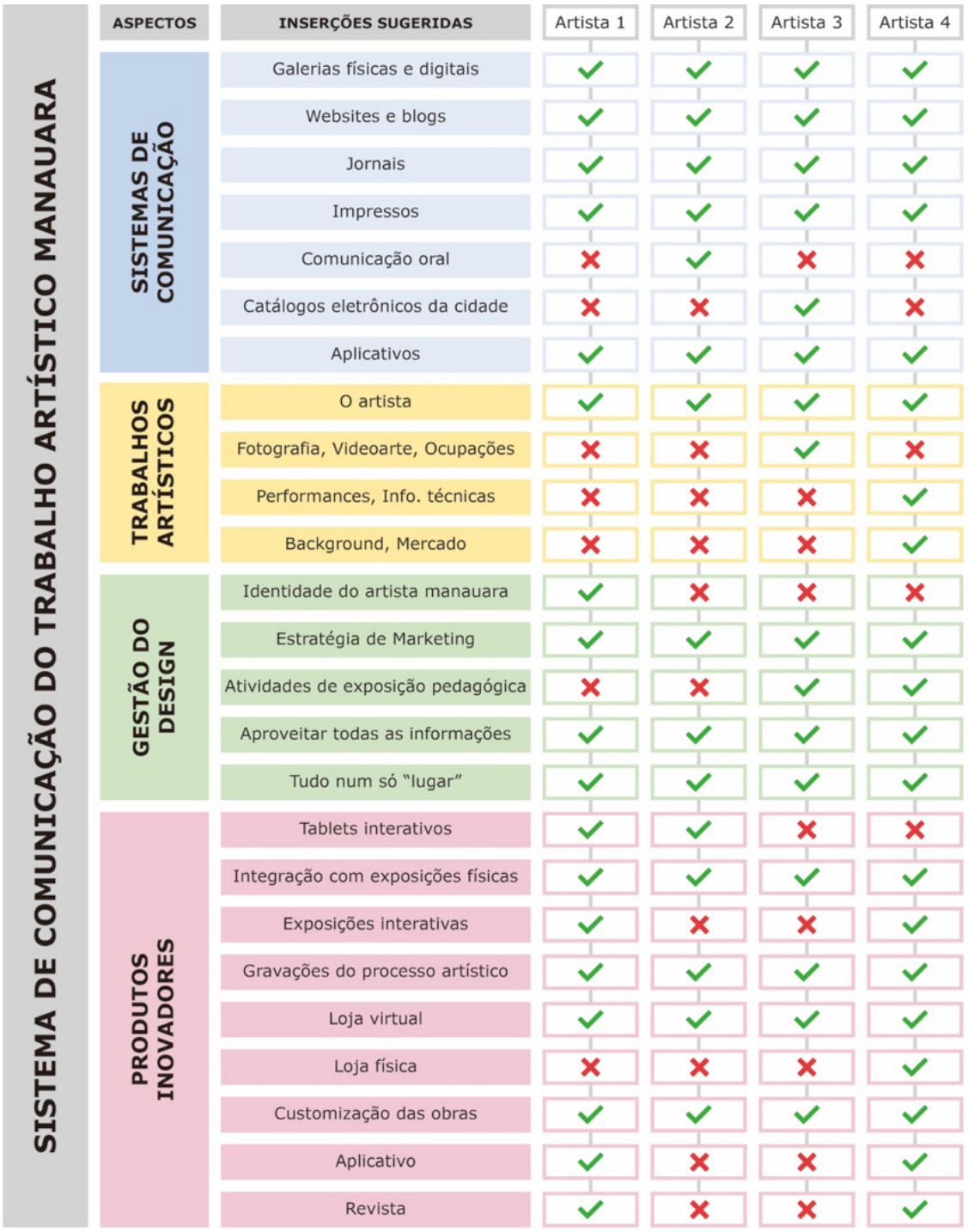

Fonte: A autora (2018). 
Análise do posicionamento... suas obras ARAUJO, Anna Lôyde Abreu de; PACHECO, Karla Mazarelo Maciel

De acordo com as inserções sugeridas em que mais houveram concordância e os que foram considerados importantes pelos especialistas, observa-se primeiramente, o aspecto "Sistema de Comunicação" Galerias físicas e digitais, websites e blogs, jornais, impressos e aplicativos. Essas sugestões apontam que o sistema precisa contemplar o uso da tecnologia digital.

Em seguida, temos o aspecto "Trabalhos Artísticos" $\rightarrow$ O artista. Essa sugestão indica que o sistema precisa comunicar o artista em si, e não apenas o seu trabalho.

Logo após, observa-se o aspecto "Gestão do Design" $\rightarrow$ Estratégia de marketing, aproveitar todas as informações, tudo num só "lugar". Essas sugestões reforçam a necessidade de haver um planejamento na concepção e monitoramento do produto.

Por fim, temos o aspecto "Produtos Inovadores" $\rightarrow$ Integração com exposições físicas, gravações do processo artístico, loja virtual, customização das obras. Todas as sugestões desse aspecto, apontam a um produto interativo com possibilidade de compra e personalização.

A partir do que foi considerado e das análises das sugestões, juntamente com os especialistas em artes, o produto a ser desenvolvido será uma loja virtual, que contenha dados sobre o perfil dos artistas da cidade, suas obras e seu processo artístico, bem como, a possibilidade de compra de suas obras, e produtos da obra aplicada. Para manter sua funcionalidade e interatividade, serão utilizados conceitos de Gestão do Design em seu planejamento e desenvolvimento. 
Projética, Londrina, v. 12, n. 1, p. 14-38, março 2021

\section{CONSIDERAÇÕES FINAIS}

Os dados apresentados nesse artigo contemplam sugestões de especialistas em artes visuais para a definição do produto mais apropriado a atuar como sistema de comunicação do trabalho artístico visual manauara.

As sugestões e discussões que surgiram durante a aplicação da técnica Focus Group, serviram para conhecer os tipos de sistemas de comunicação utilizados pelos artistas visuais na cidade para a divulgação de seus trabalhos. Além de compreender a mudança em não mais identificar os tipos de trabalhos desenvolvidos por eles, mas sim, investir na divulgação do artista em si, sem limitar suas possibilidades. Essa mudança leva a concluir a importância de envolver o público (a que se destina o projeto) na pesquisa.

Dessa forma foi possível definir, em conjunto com especialistas consultados, o produto ideal a ser desenvolvido como sistema de comunicação. Pois, os mesmos demonstraram um posicionamento favorável para o prosseguimento da pesquisa, que tem como finalidade desenvolver uma loja virtual e inseri-la no mercado.

Com isso, uma parte da pesquisa de dissertação de mestrado é contemplada, tornando viável a continuidade das investigações até chegar ao produto final da dissertação pretendida. 
Análise do posicionamento... suas obras ARAUJO, Anna Lôyde Abreu de; PACHECO, Karla Mazarelo Maciel

\section{REFERÊNCIAS}

1. CONCULTURA. A arte no Amazonas. Manaus: Fundo Municipal de Cultura, 2016. Disponível em: http://concultura.manaus.am.gov.br/wp-content/ uploads/2017/10/A-arte-no-Amazonas.pdf. Acesso em: 24 ago. 2018.

2. GIL, Antônio Carlos. Como elaborar projetos de pesquisa. 4. ed. São Paulo: Atlas, 2002.

3. GOMBRICH, Ernst Hans Josef. A História da arte. 16. ed. Rio de Janeiro: LTC, 2013. Edição de bolso.

4. KRUEGER, Richard A.; CASEY, Mary Anne. Focus groups: a practical guide for applied research. 3rd ed. Thousand Oaks, CA: Sage Publications, 2000.

5. MARCONI, Marina de Andrade; LAKATOS, Eva Maria. Fundamentos de metodologia científica. 5. ed. São Paulo: Atlas, 2003.

6. PÁSCOA, Luciane Viana Barros. O panorama das artes plásticas em Manaus. Revista Eletrônica Aboré, Manaus, ed. 03, 2007. Disponível em: http:// livrozilla.com/doc/716757/0-panorama-das-artes-pl\%C3\%A1sticas-emmanaus---revistas. Acesso em: 25 out. 2018.

7. PRATA, Wilson Silva. Design e cultura amazônica: o espaço simbólico do Campo do Design no Amazonas. 2017. Tese (Doutorado em Artes \& Design) Pontifícia Universidade Católica-PUC-Rio, Rio de Janeiro, RJ, 2017.

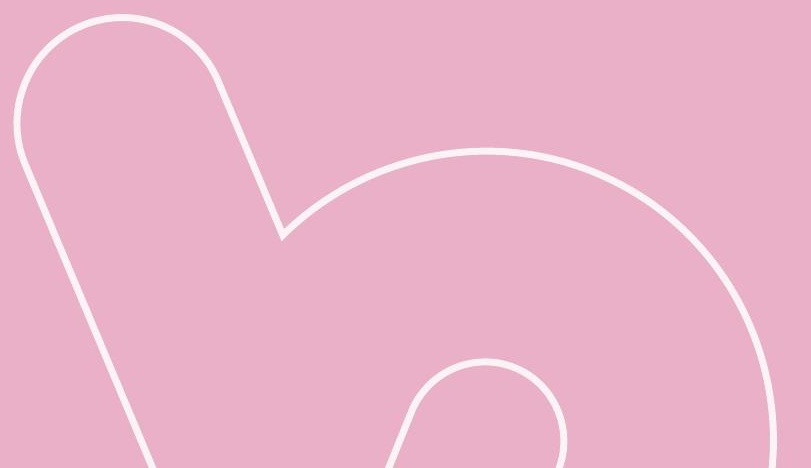


Projética, Londrina, v. 12, n. 1, p.14-38, março 2021

8. REA, Silvana. Transformatividade: aproximações entre psicanálise e artes plásticas: Reina Katz, Carlos Fajardo, Flávia Ribeiro. São Paulo: Annablume: Fapesp, 2000.

9. YIN, Robert K. Estudo de caso: planejamento e métodos. 2. ed. Porto Alegre: Bookman, 2001.

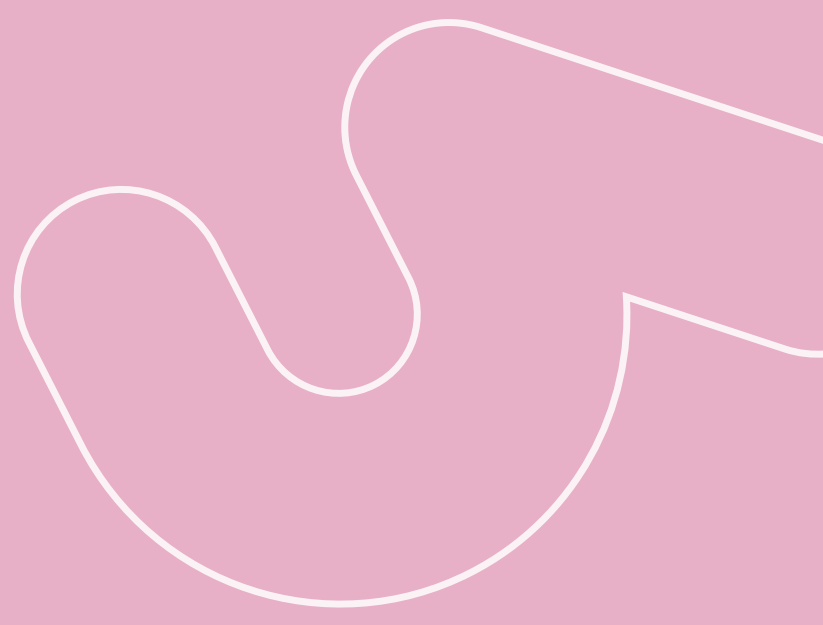

